\title{
Shear failure modes and AE characteristics of sandstone and marble fractures
}

https://doi.org/10.1515/geo-2019-0020

Received January 21, 2018; accepted Febryary 15, 2019

\begin{abstract}
To study the shear failure modes of rock fractures with different morphologies, rock types and test conditions, direct shear tests were conducted with the aid of an acoustic emission test system to obtain the characteristics of acoustic emissions in the shear process. The test results indicated that sandstone fractures experienced brittle shear failure under higher constant normal loads $(15-30 \mathrm{kN})$ and plastic shear failure under lower normal loads ( $5 \mathrm{kN}$ and $10 \mathrm{kN}$ ), while the marble fracture experienced plastic shear failure under each normal load. Dropping of shear stress, sharp change from shear dilatation to shear shrinkage and sudden release of high AE energy could be found when brittle shear failure occurred in sandstone fracture under a higher normal load. Thus, combining the location evolution characteristics of acoustic emission, it can be concluded that the entire shear dislocation of sandstone fracture in brittle shear failure mode happened just after the peak under higher normal loads. However, the entire shear dislocation of sandstone fracture under lower normal loads and marble fracture under all normal loads occurred just at the beginning of the shear process.
\end{abstract}

Keywords: rock fracture; direct shear test; acoustic emission; 3D morphology; shear failure mechanism

\footnotetext{
*Corresponding Author: Baohua Guo: School of Energy Science and Engineering, Henan Polytechnic University, Jiaozuo, 454000, Henan, P. R. China

Collaborative Innovation Centre of Coal Work Safety, Jiaozuo, 454000, Henan, P. R. China

Key Laboratory of Safety and High-efficiency Coal Mining, Ministry of Education (Anhui University of Science and Technology), Huainan, 232001, Anhui, P. R. China

E-mail: guobaohua@139.com; Tel: +8613949669615

Hangyu Dong: School of Resources and Civil Engineering, Northeastern University, Shenyang, 110004, Liaoning, P. R. China
}

\section{Introduction}

Many geological discontinuities (such as joints and faults) existing in natural rock mass greatly influence the rock mass stability. To prevent engineering accidents caused by rock discontinuities, it is important to determine the deformation characteristics and the shear failure modes of rock fractures. Different scales of asperities play an important role in the mechanical behaviors of rough rock fractures, thus better understanding of contact condition or morphology of rock fracture may help to understand the shear failure mechanism.

Numerous laboratory investigations have focused on the asperity damage under the combined action of normal stress and shear stress. Hutson and Dowding [1] sheared cyclically about 30 real granite and limestone joints to measure asperity degradation under normal stresses and displacements consistent with earthquake loading. Huang et al. [2] conducted a laboratory investigation of the mechanical behavior of initially closely mated joints in rock undergoing small sliding displacements to elucidate the features of joint behavior such as dilatation, damage of surface roughness, cyclic sliding behavior and the dependence of these phenomena on stress level and sliding history. Pereira et al. [3] studied the shear failure of a profiled and clean discontinuity artificially prepared from natural sandstone using direct shear tests, in which the behavior of the rock surfaces during shear could be continuously observed. Wang and Scholz [4] studied experimentally the frictional wear of rock and found that the loss of material from the interface of two bodies during frictional sliding was a function of normal stress and the initial roughness of the sliding surface. Indraratna et al. [5] described the asperity deformation under constant normal stiffness boundary conditions based on 3D scanned models, in which asperity height deviation $(\Delta z)$ was used to characterize asperity deformation. Byerlee [6] considered that asperities were crushed to a certain extent when the tensile stress exceeded the tensile strength of asperities. Based on the influence of the inclination and numbers of asperities on shear behaviors, Patton [7] described the sliding and cutting failure modes of asperities and proposed a 
shear strength formula. Wang and Xie $[8,9]$ studied the degradation and evolution of rock fracture surface roughness by fractal dimension during the shear process. Xie et al. [10] concluded that more rough joints will have lower normal stiffness and higher shear stiffness through investigating the contact mechanical behavior of the rock joints by using the photoelasticity method.

Acoustic emission (AE) phenomenon, which is generated spontaneously by the rapid release of energy from microcracking within brittle rock and metal materials, has been extensively studied. Lockner [11] gave a detailed overview on the study of rock failure through use of the $\mathrm{AE}$ method, which can provide information about the size, location of the acoustic events and deformation mechanisms of materials $[12,13]$. Thus, a micro crack in a rock specimen could be detected by recording AE signals, as well as a planar location of $\mathrm{AE}$ sources using the $\mathrm{AE}$ method during the whole shear process for rock fractures [14-16]. As examples, Hong et al. [17] investigated acoustic emission (AE) characteristics of rock-concrete interfaces under shear loading. Son et al. [18] conducted laboratory shear tests under constant normal stiffness (CNS) and constant normal load or constant stress (CNL) conditions and thought that the asperities damage may be correlated with asperity height according to the distribution of AE source locations.

Overall, many works have been done to reveal the shear failure mechanism of rock fracture, and some progresses have been achieved. However, the influences of normal stress and fracture surface morphology on the shear failure mechanism of rock fracture are not fully understood yet, meaning it is necessary to further study the shear failure mechanism of rock fracture with the help of the AE method and 3D scanning technology. Thus, direct shear tests were conducted on sandstone and marble specimens containing a single fracture under different CNL conditions, in which the AE method was used to monitor the shear failure process of rock fracture while 3D scanning technology were used to obtain the initial 3D morphology of rock fracture surfaces.

\section{Sample preparation, test apparatus and methodology}

\subsection{Sample preparation}

Standard cylindrical specimens with a diameter and a length of approximately $50 \mathrm{~mm}$ and $100 \mathrm{~mm}$ were prepared, and their physical and mechanical properties are shown in Table 1, in which cohesion (c) and internal friction angle $(\varphi)$ of rock specimens were obtained through traditional triaxial compression tests on standard cylindrical specimens. Tensile strength $\left(\sigma_{t}\right)$ was obtained through brazilian split tests. Uniaxial compression strength (UCS), Poisson ratio $(\mu)$ and elastic modulus $(E)$ of rock specimens were obtained through uniaxial compression tests. Basic friction angle $\left(\varphi_{b}\right)$ was obtained from residual shear tests on flat unweathered rock surfaces [19].

Tensile fractures were produced at or near the midheight of specimens by a self-made split tool [20]. Six artificial fractures of sandstone (group S, named as S1, S2, S3, $\mathrm{S} 4, \mathrm{~S} 5$, and S6) and marble (group A, named as A1, A2, A3, A4, A5 and A6), as shown in Figure 1 (a), were prepared for the direct shear tests. Accordingly, a specimen was composed of upper half, rock fracture and lower half.

Figure 1(b) shows the encapsulation of a specimen, in which the rock fracture was as parallel to the shear direction as possible. As we can see in Figure 1(b), the lower half of the specimen was concentrically fixed by cement as much as possible into the lower ring. After the cement in the lower ring solidified, the holding rods and the upper shear ring were placed one by one, in which the holding rods were used to isolate the upper shear ring and the lower shear ring, and the upper shear ring was concentric with the lower shear ring. Then, rubber mud with width of $10 \mathrm{~mm}$ was laid on the top surface of the cement in the lower ring to isolate the cement in the upper shear ring and that in the lower shear ring, and then cement was poured into the upper shear ring. After the cement in the upper shear ring solidified and reached its designed strength, the holding rods were removed, and then the specimen encapsulated by the upper and lower shear rings was put into the shear boxes to carry out the shear test.

\subsection{Test apparatus}

Direct shear tests of rock fractures were conducted using the direct shear test system (RDS-200) designed by Geotechnical Consulting and Testing Systems (GCTS), as shown in Figure 2 (Left) [21], which automatically controlled shear and normal load by the electro-hydraulic servo system. The shear and normal load capacities of the RDS-200 are $100 \mathrm{kN}$ and $50 \mathrm{kN}$, whereas the shear and normal strokes are $25 \mathrm{~mm}$ and $24 \mathrm{~mm}$, respectively. The normal and shear displacement were measured by using precise LVDT. As we can see in the cross-section of shear box in Figure 2, the specimen containing a single horizontal fracture was fixed in the center position of the shear boxes by cement, the fracture will bear all normal and 
Table 1: Mechanical property of rock specimens. $\varphi_{b}$-Basic friction angle; UCS-Uniaxial compression strength; $c$-Cohesion; $\varphi$-Internal friction angle; $\sigma_{t}$-Tensile strength; $E$-Elastic modulus; $\mu$-Poisson ratio.

\begin{tabular}{ccccccccc}
\hline Group & Rock type & $\varphi_{b} /^{\circ}$ & $\mathrm{UCS} / \mathrm{MPa}$ & $c / \mathrm{MPa}$ & $\varphi /^{\circ}$ & $\sigma_{t} / \mathrm{MPa}$ & $\mathrm{E} / \mathrm{GPa}$ & $\mu$ \\
\hline $\mathrm{S}$ & Sandstone & 30.00 & 78.43 & 21.452 & 46.0 & 3.76 & 24.58 & - \\
$\mathrm{A}$ & Marble & 31.04 & 141.68 & 50.903 & 25.8 & 15.14 & 83.87 & 0.38 \\
\hline
\end{tabular}

shear loads because there was a gap with width of about $10 \mathrm{~mm}$ between upper and lower cements.

The OKIO 3D scanner system designed by TenYoun 3D Technology Corporation and Tsinghua University was used to obtain initial 3D morphology of the rock fracture surfaces, as shown in Figure 3 (left), and the 3D scanning results of the upper and lower rock fractures of a rock specimen is shown in Figure 3 (right) [21] as an example. The global error control module was included to control the scanning accuracy of rock surface morphology. The average scanning accuracy is $0.02-0.03 \mathrm{~mm}$, and the scanner can cover a maximum scanning area of $400 \times 300 \mathrm{~mm}^{2}$.

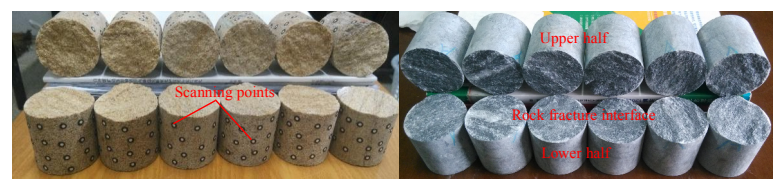

(a) Tensile fractures of sandstone (left) and marble (right)

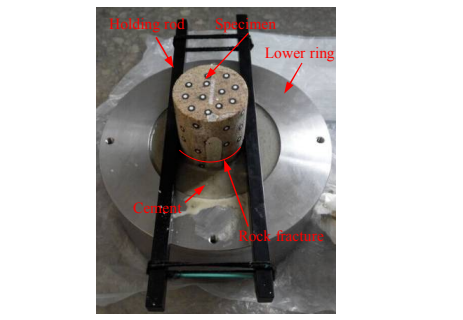

Figure 1: Tensile fractures of sandstone and marble and the encapsulation of a single fractured rock specimen. The scanning points (black circle with white dot) pasted on the sandstone specimen surface are used for 3D scanning location.

The AE signals during the shear process were monitored by the AE test and analysis system (DS-2), as shown in Figure 4(a). Four AE sensors with a frequency response range of $60-400 \mathrm{kHz}$ were used for locating $\mathrm{AE}$ signals. The arrangement of the four sensors is shown in the left part of Figure 4(b), while the installation details of an AE sensor are shown in the right part of Figure 4(b). As we can see in Figure 4(b), four AE sensors were arranged on top surface of the upper shear box equidistantly on a circumferential line; a coupling agent was applied to couple the gap between the sensor's ceramic surface and the top surface of

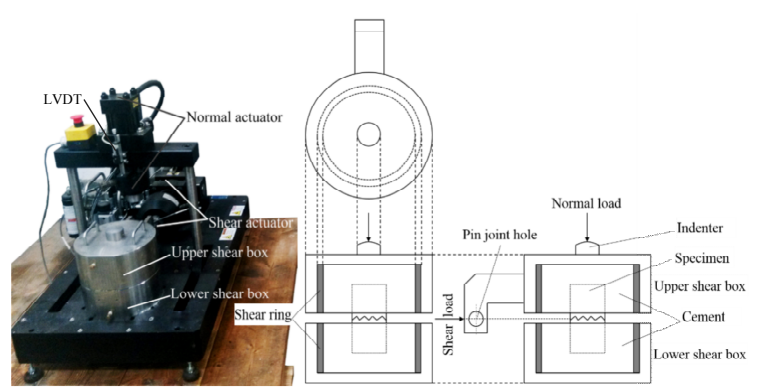

Figure 2: RDS-200 direct shear testing system (left) and crosssection of shear box (right) [21]
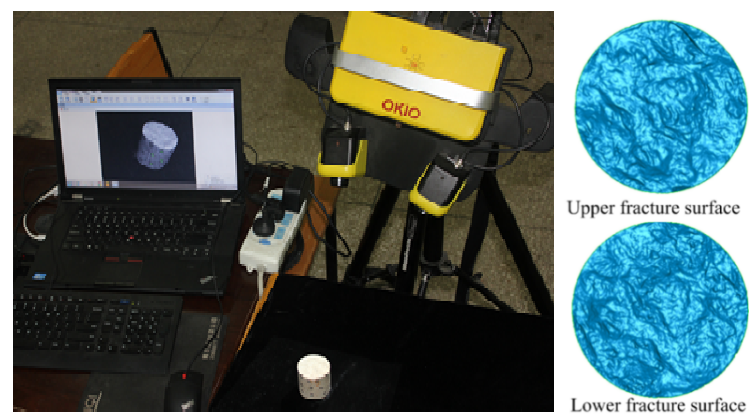

Figure 3: OKIO 3D scanner system (left) and 3D view of the fracture surfaces (right) [20]

the upper shear box, then the sensor was fixed with a tool to prevent it becoming loose. The sampling frequency of the $\mathrm{AE}$ test and analysis system is $3 \mathrm{MHz}$ and the threshold value is $40 \mathrm{~dB}$. After $\mathrm{AE}$ testing was completed, the $\mathrm{AE}$ data can be derived for offline analysis.

\subsection{Methodology}

After being scanned by the OKIO 3D scanner system to obtain the morphological data, the specimen fractures of two groups (S1-S6 and A1-A6) were sheared through using a direct shear test system (RDS-200) under six CNL conditions with increased normal load levels of $5 \mathrm{kN}, 10 \mathrm{kN}, 15 \mathrm{kN}$, $20 \mathrm{kN}, 25 \mathrm{kN}$ and $30 \mathrm{kN}$, respectively. The normal load was applied firstly with the loading rate of $20 \mathrm{kPa} / \mathrm{sec}$, then the shear displacement was applied with a constant shear- 

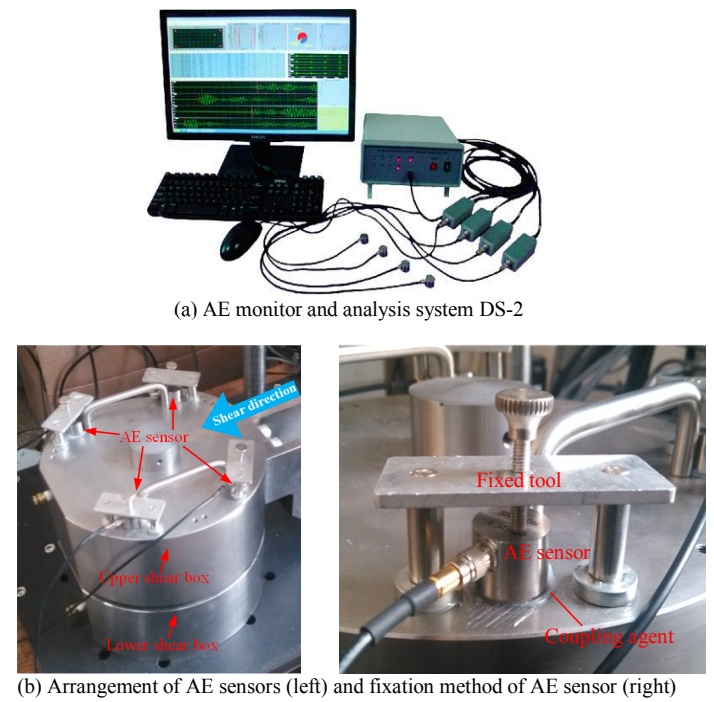

Figure 4: $A E$ test and analysis system DS-2.

ing rate of $1 \mathrm{~mm} / \mathrm{min}$. The maximum shear displacements were set at approximately $5 \mathrm{~mm}$ for sandstone fractures and $10 \mathrm{~mm}$ for marble fractures. Acoustic emission (AE) monitoring was carried out throughout each shear test to obtain the AE characteristics during shearing of rock fractures.

\section{Shear test results of sandstone and marble fractures}

\subsection{Shear stress-shear displacement curves}

The complete shear stress-shear displacement curves of sandstone and marble fractures under various CNL conditions are shown in Figure 5(a) and (b). From Figure 5(a) and (b) we can see that the shape of pre-peak curves of sandstone and marble fractures are similar with each other, but their post-peak curves are different obviously. Specifically, the shear stress of sandstone fractures under normal loads of 15-30 kN dropped suddenly after the peak, while those of marble fractures under all normal loads and sandstone fractures under lower normal loads of $5 \mathrm{kN}$ and $10 \mathrm{kN}$ decreased gradually after the peak.

Based on the shear stress-shear displacement curves, the peak shear stress $\left(\tau_{p}\right)$, peak shear displacement $\left(\delta_{p}\right)$, pre-peak shear stiffness $\left(k_{s}\right)$, drop gradient $\left(k_{d}\right)$ [21] and residual friction coefficient $\left(f_{r}\right)$ could be obtained, in which peak dilatancy angle $\left(d_{n}\right)$ was back calculated with the Barton formula [19]. Because the contact area changed along with the shear displacement, the normal stress also changed under the CNL condition. So, the peak normal stress $\left(\sigma_{p}\right)$ was defined as the normal stress at the peak shear stress. Figure 6a)-(f) shows the relationships between peak shear strength $\left(\tau_{p}\right)$, peak shear displacement $\left(\delta_{p}\right)$, peak dilatancy angle $\left(d_{n}\right)$, pre-peak shear stiffness $\left(k_{s}\right)$, drop gradient $\left(k_{d}\right)$ and residual friction coefficient $\left(f_{r}\right)$ and peak normal stress $\left(\sigma_{p}\right)$. In Figure 6(a) and (b), there were highly positive linear relationships between peak shear strength $\left(\tau_{p}\right)$, peak shear displacement $\left(\delta_{p}\right)$ and peak normal stress $\left(\sigma_{p}\right)$, respectively. In Figure 6(c) and Figure 6(d), there were inverse proportional relations between peak dilatancy angle $\left(d_{n}\right)$, residual friction coefficient $\left(f_{r}\right)$ and peak normal strength $\left(\sigma_{p}\right)$ on the whole. Because peak dilatancy angle $\left(d_{n}\right)$ was back calculated with Barton formula, it might appear with negative values; this phenomenon also could be seen in Figure 6(c). Because of the degradation of asperities on rock fracture surface in shear process, the fracture surface tended to be smoother and the residual friction coefficient $\left(f_{r}\right)$ of fracture surface decreased at residual friction stage as peak normal stresses increased. In Figure 6(e), there existed positive linear correlation between pre-peak shear stiffness $\left(k_{s}\right)$ and peak normal stress for marble specimens, but it was not so obvious for the sandstone specimen. Pre-peak shear stiffness of marble fracture was lower than sandstone fracture under the same lower normal load, but it was higher than sandstone fracture under the same higher normal load. The shear stress-shear displacement curves of marble fractures experienced a smoother decrease than sandstone fractures after the peak, while the shear stress of sandstone fracture decreased sharply within an extremely short shear displacement or time, especially under higher normal stresses as shown in Figure 5(a) and (b), which resulted in a big drop gradient. In Figure 6(f), the post-peak drop gradient of sandstone fractures shows a good exponential relationship while that of marble fractures shows a linear relationship with peak normal stress.

\subsection{Normal displacement-shear displacement curves}

Figure 7 shows the normal displacement-shear displacement curves of sandstone and marble fractures under various CNL conditions, in which the positive and negative normal displacements reflect shear shrink and shear dilatation respectively. Thus, as we can see in Figure 7(a) and (b), shear dilatation occurred in sandstone and marble fractures under normal loads of $5 \mathrm{kN}$ and $10 \mathrm{kN}$, while shear shrink occurred under normal loads of being equal to or higher than $15 \mathrm{kN}$ near the shear displacements of 


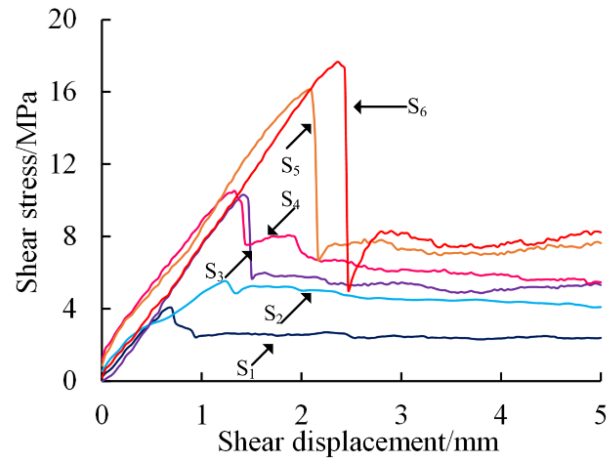

(a) Group S (Sandstone fractures)

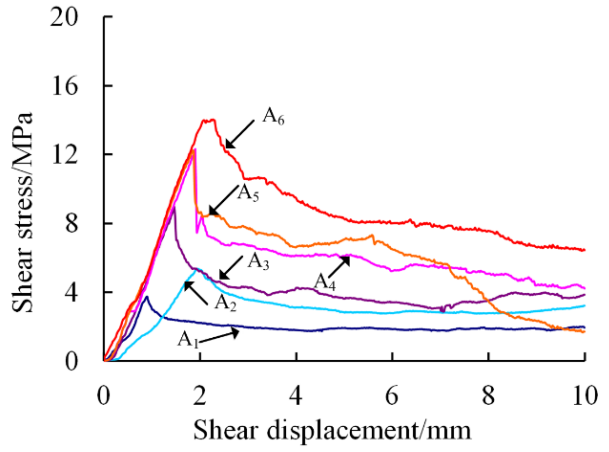

(b) Group A (Marble fractures)

Figure 5: Shear stress-shear displacement curves of sandstone fractures (Group S) and marble fractures (Group A). Group S includes S1 $(\mathrm{CNL}=5 \mathrm{kN}), \mathrm{S} 2(\mathrm{CNL}=10 \mathrm{kN}), \mathrm{S} 3(\mathrm{CNL}=15 \mathrm{kN}), \mathrm{S} 4(\mathrm{CNL}=20 \mathrm{kN}), \mathrm{S} 5(\mathrm{CNL}=25 \mathrm{kN})$ and $\mathrm{S} 6(\mathrm{CNL}=30 \mathrm{kN})$, and Group $\mathrm{A}$ includes $\mathrm{A} 1(\mathrm{CNL}=$ $5 \mathrm{kN}), \mathrm{A} 2(\mathrm{CNL}=10 \mathrm{kN}), \mathrm{A} 3(\mathrm{CNL}=15 \mathrm{kN}), \mathrm{A} 4(\mathrm{CNL}=20 \mathrm{kN}), \mathrm{A} 5(\mathrm{CNL}=25 \mathrm{kN})$ and $\mathrm{A} 6(\mathrm{CNL}=30 \mathrm{kN})$.

$5 \mathrm{~mm}$. However, when the normal loads were equal to or higher than $15 \mathrm{kN}$, sandstone and marble fractures also experienced a stage of shear dilatation, otherwise, when the normal loads were $5 \mathrm{kN}$ or $10 \mathrm{kN}$, there was almost no shear dilatation occurred in the whole shear process.

Besides, the normal deformation showed different changing trends before and after the peak. It is mentioned here that the horizontal coordinate of the colored solid dots on the normal displacement-shear displacement curves are used to mark the peak shear displacements. As for sandstone fractures under the normal loads of $15-30 \mathrm{kN}$, the normal displacement decreased before the peak and increased sharply just after the peak shear displacement except for specimen S4, which were corresponding to the sudden drop of the shear stress as show in Figure 5(a). But for marble fractures under the normal loads of $15-30 \mathrm{kN}$, normal displacement increased before the peak and decreased gradually after the peak, which were corresponding to the gradual decrease of the shear stress as show in Figure 5(b).

\subsection{AE characteristics of sandstone and marble fractures during shear process}

The relationships between AE energy and shear displacement of the sandstone and marble specimens are shown in Figure 8 and 9, respectively. It is apparent that the high $\mathrm{AE}$ energy of sandstone fractures except for S1 and S2 in Figure 8 was mainly released right after the peak. However, high AE energy of marble fractures in Figure 9 was generally released in the whole pre-peak stage from the beginning of the shear test. Because the constant normal loads were lower, the released $\mathrm{AE}$ energy of sandstone fracture
S1 and S2 was lower than other sandstone specimens under a higher normal load and their AE energy didn't release simultaneously just after the peak. For marble fractures, a lot of AE energy was released many times before the peak, thus there was no higher AE energy released just after the peak.

The peak AE energy $\left(E_{p}\right)$ of sandstone fracture is about two orders of magnitude higher than marble fractures during the whole shear process, and it has close correlation with both normal loads and morphology characteristics of sandstone fractures. Thus, formula (1) was fitted to represent the relationships of the peak AE energy $\left(E_{p}\right)$ with normal load and root-mean-square deviation of the profile $\left(S_{q}\right)$ of sandstone fractures.

$$
E_{p}=p_{1}+p_{2} \cdot \ln (N)+p_{3} \cdot S_{q} \quad\left(R^{2}=0.97\right)
$$

In formula (1), $N$ is normal load, kN. Constants $\mathrm{p}_{1}, \mathrm{p}_{2}$ and $\mathrm{p}_{3}$ are $-1.34 \times 10^{6}, 4.36 \times 10^{5}$ and $1.20 \times 10^{6}$, respectively. The 3D fitted surface graph of formula (1) and test data is shown in Figure 10. It could be seen in Figure 10 that $E_{p}$ increased with increasing normal load and $S_{q}$. Therefore, the released AE energy could be estimated by its normal load and the root-mean-square deviation of the profile $\left(S_{q}\right)$ of fracture surface when a sandstone fracture fails, which could be used for prevention and control of dynamic disaster relevant to rock fracture.

Taking sandstone fracture S6 and marble fracture A1 as samples, Figure 11 shows the relationships among the $\mathrm{AE}$ energy, duration, counts, amplitude and peak frequency during the whole shear process. In Figure 11(a), solid black dots represent AE events in X-Y-Z 3D space, red solid squares represent their projections on the X-Y plane to describe the relationship between AE counts and duration, blue solid triangles represent their projections on 

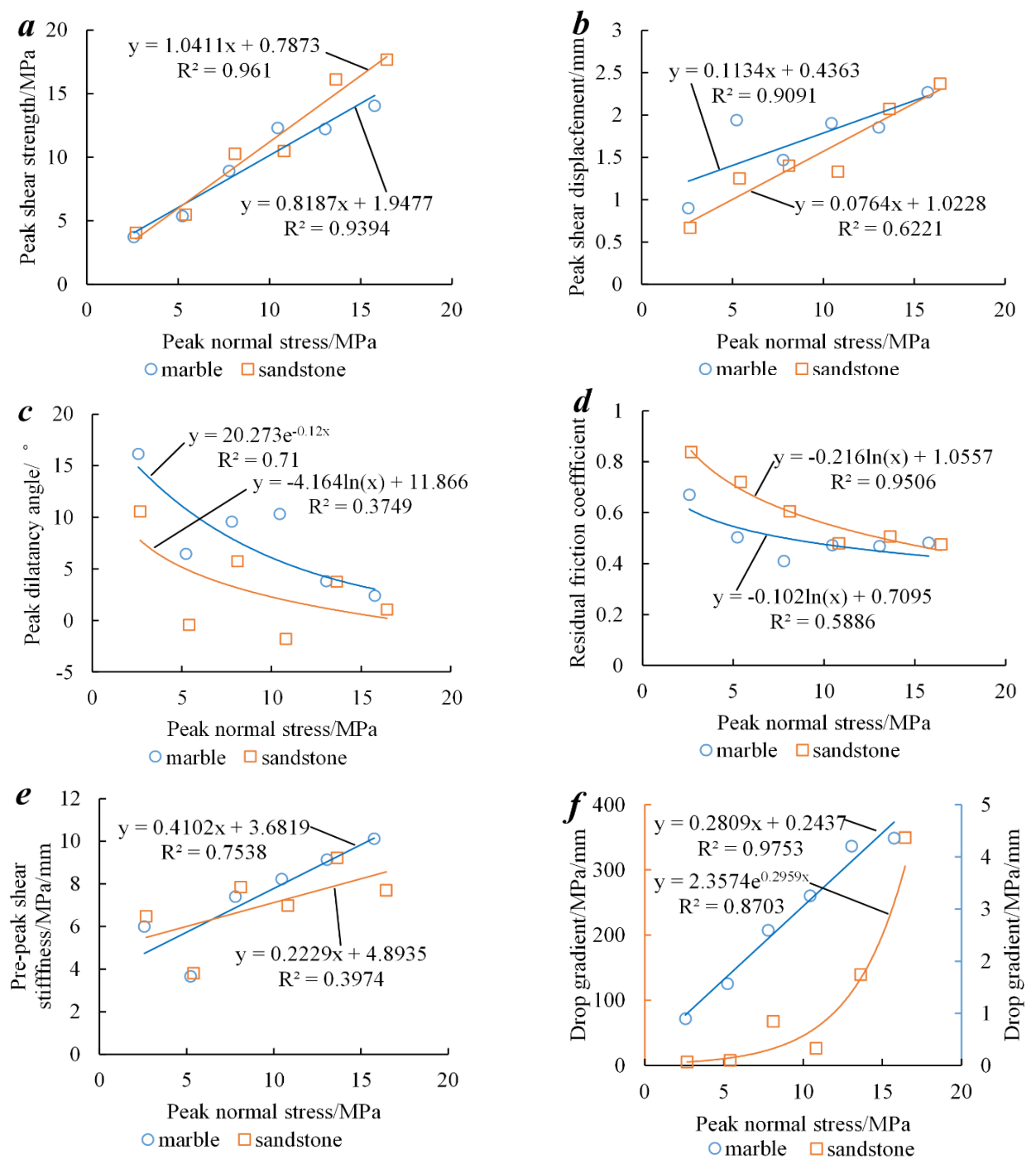

Figure 6: Relationships between shear parameters and peak normal stress: (a) Peak shear strength vs. peak normal stress; (b) Peak shear displacement vs. peak normal stress; (c) Peak dilatancy angle vs. peak normal stress; (d) Residual friction coefficient vs. peak normal stress; (e) Pre-peak shear stiffness vs. peak normal stress; (f) Drop gradient vs. peak normal stress.

the Y-Z plane to describe the relationship between AE energy and counts, and green solid pentagons represent their projections on the X-Z plane to describe the relationship between AE energy and duration. In Figure 11(b), solid black dots represent AE events in X-Y-Z 3D space, red solid squares represent their projections on the X-Y plane to describe the relationship between $\mathrm{AE}$ amplitude and peak frequency, blue solid triangles represent their projections on the Y-Z plane to describe the relationship between $\mathrm{AE}$ energy and amplitude, and green solid pentagons represent their projections on the X-Z plane to describe the relationship between $\mathrm{AE}$ energy and peak frequency.
As we can see from Figure 11, AE energy, duration, counts and amplitude show positive relationships with each other on the whole, except for the relationship between AE energy and amplitude of sandstone fracture S6. Besides, five typical AE signals highlighted in red loops with very high energy, count, duration and very low amplitude in sandstone fracture $\mathrm{S} 6$ were generated just after the peak. Thus, it was deduced that these typical AE signals could be used to monitor the failure of sandstone fracture. However, there were no similar typical AE signals in marble fracture A1 that can be used to monitor the failure of marble fracture. Besides, the dominant peak frequencies of $\mathrm{AE}$ waveform were about $75 \mathrm{kHz}$ and $180 \mathrm{kHz}$ in 


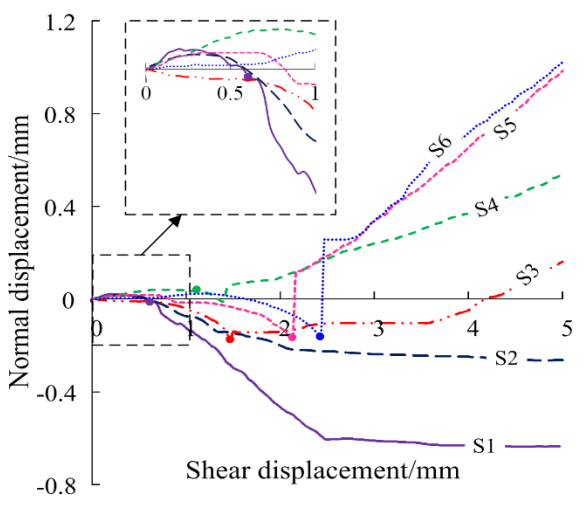

(a) Sandstone fractures

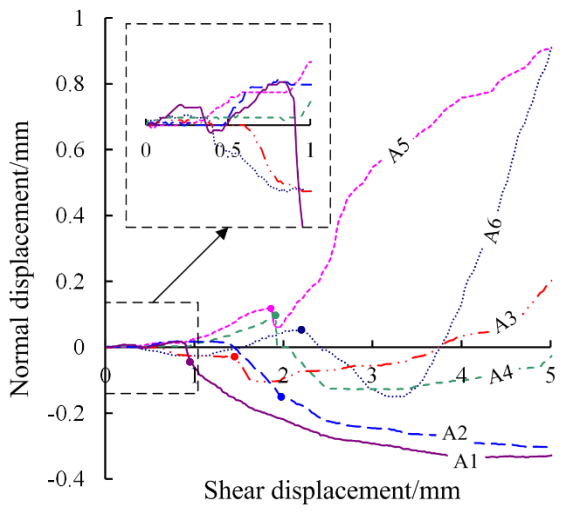

(b) Marble fractures

Figure 7: Normal displacement - shear displacement curves of sandstone fractures (Group S) and marble fractures (Group A) . Group $S$ includes S1 $(\mathrm{CNL}=5 \mathrm{kN}), \mathrm{S} 2(\mathrm{CNL}=10 \mathrm{kN}), \mathrm{S} 3(\mathrm{CNL}=15 \mathrm{kN}), \mathrm{S} 4(\mathrm{CNL}=20 \mathrm{kN}), \mathrm{S} 5(\mathrm{CNL}=25 \mathrm{kN})$ and S6 $(\mathrm{CNL}=30 \mathrm{kN})$, and Group A includes A1 $(\mathrm{CNL}=5 \mathrm{kN}), \mathrm{A} 2(\mathrm{CNL}=10 \mathrm{kN}), \mathrm{A} 3(\mathrm{CNL}=15 \mathrm{kN}), \mathrm{A} 4(\mathrm{CNL}=20 \mathrm{kN}), \mathrm{A} 5(\mathrm{CNL}=25 \mathrm{kN})$ and $\mathrm{A} 6(\mathrm{CNL}=30 \mathrm{kN})$. The colored solid dots on the curves correspond to the peak shear displacements. The curves in the big box are the enlarged graphs of the curves in the small box in Figure 7 (a) and (b).

both sandstone and marble fractures. And the energy of AE signals with a peak frequency of about $75 \mathrm{kHz}$ was higher on the whole than those with a peak frequency of about $180 \mathrm{kHz}$. The peak frequency of the typical AE signals was about $75 \mathrm{kHz}$, which can be used as a signal to confirm the shear failure of sandstone fracture.

\section{Discussions}

\subsection{Shear failure mechanisms of rock fracture}

In order to explain the shear failure mechanism of rock fracture, the shear failure model of rock fracture is built as shown in Figure 12(a). The simplified contact modes mainly consist of two contact types including a flat top surface contact type (a1, a5 and a8) and an inclining slope surface contact type (a2-a4, a6, a7). Generally speaking, the asperities in the flat top surface contact type bear more normal load $N$ and less shear load $T$ while the asperities in the inclining slope surface contact type bear more shear load and less normal load. When the normal load is applied on the upper end of the rock specimen, more asperities on both the upper and lower rock fracture surfaces will be in contact with each other. The normal deformation of rock fracture will increase and the overlap height $h$ between the contacted asperities in the inclining slope surface contact type will also increase with increasing normal load. It can be deduced that the friction angle of the asperity surface, the overlap height $h$ and the climbing angles of the contacted asperities in the inclining slope surface contact type determine the shear resistance of rock fracture.

As we are discussing the shear bearing capacity of contacted asperities in two types of contact modes here. For convenience, failure mode of a rock fracture asperity is shown in Figure 12(b) and (c) to help understand the failure mode of a rock fracture asperity. Figure 12(b) shows the stress condition of rock specimen with a single fracture and Figure 12(c) shows the relationship between the MohrCoulomb strength line and the Mohr stress circle in Mohr stress space. Failure does not occur if the Mohr-Coulomb strength line and the Mohr stress circle do not intersect. Otherwise, when the Mohr-Coulomb strength line and the Mohr stress circle intersect with each other and the angle $\beta$ in Figure 12(b) is between half $\angle \sigma_{1} \mathrm{BR}$ and half $\angle \sigma_{1} \mathrm{BQ}$, the sliding failure along the existed fracture will occur, but if $\beta$ is beyond the range between half $\angle \sigma_{1} \mathrm{BR}$ and half $\angle \sigma_{1} \mathrm{BQ}$, the rock specimen will fail in the cutting failure mode along a new generated fracture.

However, it is different for the failure of the contacted asperities on the rock fracture surface and a rough rock fracture, because the failure of some asperities may not lead to an overall failure of the rock fracture. As the shear load increases continually, one asperity will slide along the slope of another contacted asperity until one of the two contacted asperities be cut off at a certain height. Therefore, the shear bearing capacity of the asperities consist of three parts including horizontal sliding friction (a1, a5, 

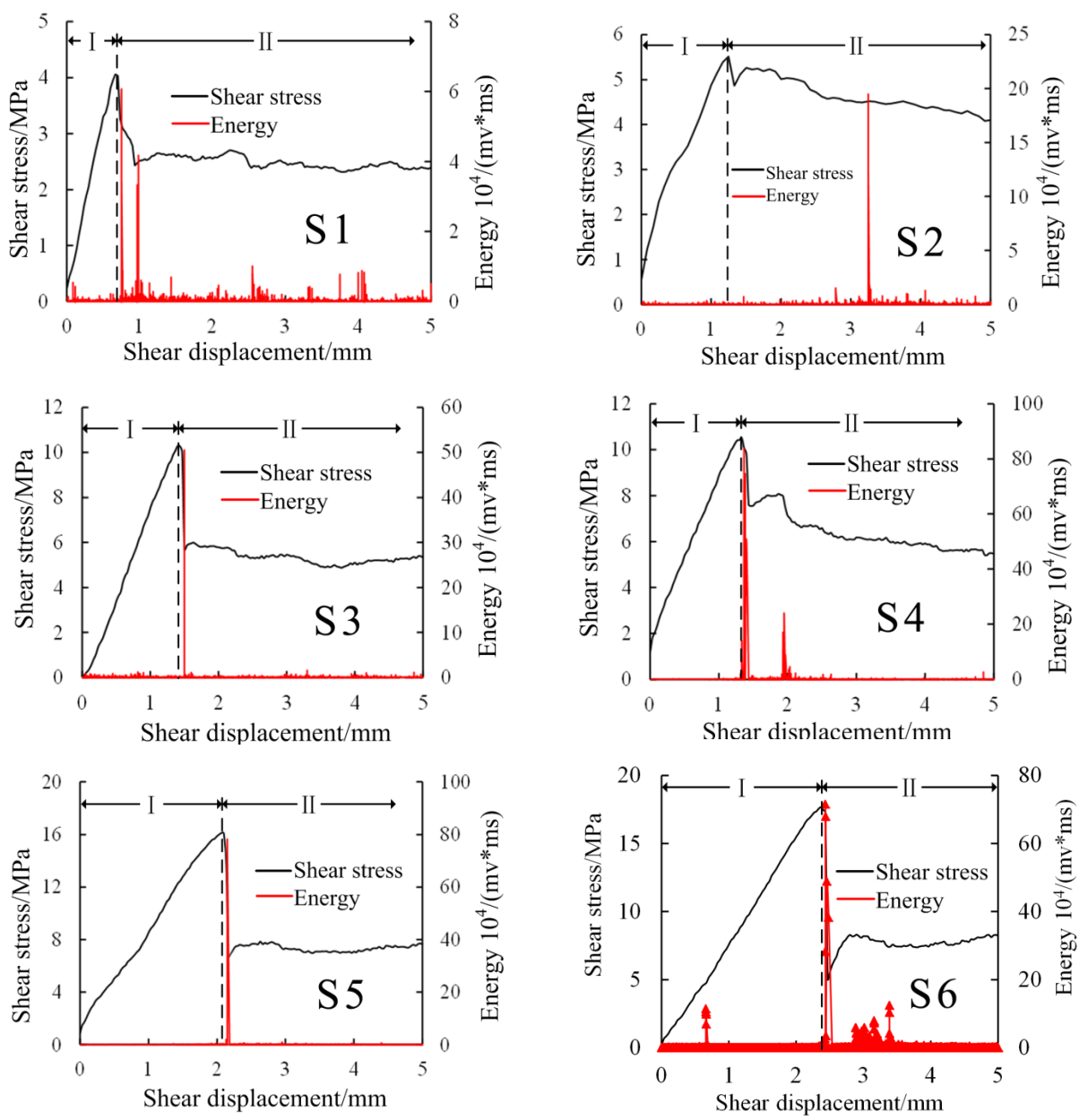

Figure 8: Energy and shear stress evolution along shear displacement of sandstone fractures. Test conditions are as follows: $\mathrm{S} 1$ (CNL= 5 $\mathrm{kN}), \mathrm{S} 2(\mathrm{CNL}=10 \mathrm{kN}), \mathrm{S} 3(\mathrm{CNL}=15 \mathrm{kN}), \mathrm{S} 4(\mathrm{CNL}=20 \mathrm{kN}), \mathrm{S} 5(\mathrm{CNL}=25 \mathrm{kN})$ and $\mathrm{S} 6(\mathrm{CNL}=30 \mathrm{kN})$.

a8), direct cutting (a2, a3, a4) and cutting after climbing friction (a6, a7). The red triangle zones of the asperities in Figure 12(a) will be cut off under a certain normal and shear stress functions.

When the normal load is lower, the overlap height $h$ will be small, more asperities will fail in direct cutting mode, thus the shear dilatation and the elastic energy stored in asperities will be less, and the slope of softening stage of the post-peak shear stress-shear displacement curves will be also smaller. When the normal load is higher, more asperities will fail in cutting after climbing friction mode, thus there will be obvious shear dilatation occur and more elastic energy stored in asperities before failure, and the slope of softening stage of the post-peak shear stress- shear displacement curves will be larger.

\subsection{Shear failure modes of sandstone and marble fractures}

Shear failure modes of sandstone and marble fractures depend on the accumulation (before the peak) and sudden release (after the peak) of elastic energy. When a high $\mathrm{AE}$ energy releases suddenly and simultaneously just after the peak, the failure is defined as a brittle one; otherwise, the failure is defined as a plastic one. For mated rock fractures, the higher the rock fracture roughness and the constant normal stress are, the more the stored elastic energy in contacted asperities is. When above accumulated elastic energy release simultaneously after the peak, the shear failure of rock fracture will show obvious brittle behavior; otherwise, when the elastic energy cannot be accumulated for lower fracture roughness or lower normal stress, or most asperities were worn down one by one before the peak, the phenomenon of simultaneous elastic energy re- 

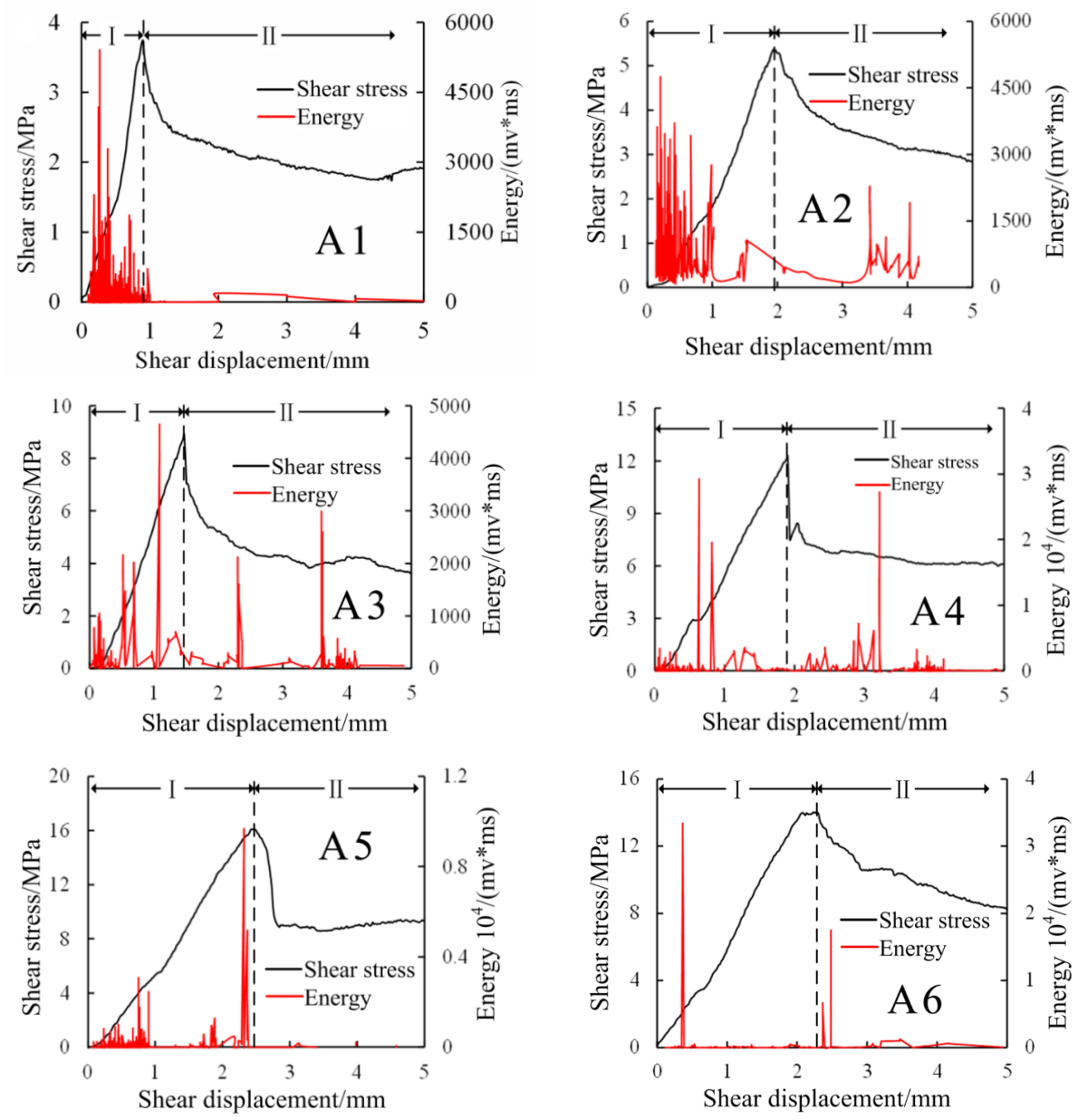

Figure 9: Energy and shear stress evolution along shear displacement of Marble fractures. Test conditions are as follows: $A 1$ (CNL= $5 \mathrm{kN}$ ), $\mathrm{A} 2$ $(\mathrm{CNL}=10 \mathrm{kN}), \mathrm{A} 3(\mathrm{CNL}=15 \mathrm{kN}), \mathrm{A} 4(\mathrm{CNL}=20 \mathrm{kN}), \mathrm{A} 5(\mathrm{CNL}=25 \mathrm{kN})$ and $\mathrm{A} 6(\mathrm{CNL}=30 \mathrm{kN})$.

lease cannot occur and the shear failure of rock fracture cannot show obvious brittle behavior. So far, we can judge the brittle failure of sandstone fracture under higher normal loads by the following three ways such as (1) the sudden drop of shear stress just after the peak, (2) the quick transform from shear dilatation to shear shrinkage just after the peak, and (3) the sudden simultaneous release of higher elastic energy just after the peak.

According to Figure 5 and Figure 6(f) in section 3.1, the post-peak drop gradient of sandstone fracture increased quickly with increasing normal load, and it was about two orders of magnitude higher than marble fractures under high normal loads. The sandstone fractures might fail in a brittle state under a higher normal load for their shear stress drop suddenly just after the peak, while the marble fractures under each normal load and the sandstone fractures under lower normal loads might fail in a plas- tic state for most of their shear stress decreased gradually after the peak. It should be noted that, as shown in Table 1, even though the UCS of marble (141.68 MPa) was higher than sandstone ( $78.43 \mathrm{MPa})$, the failure of marble fracture didn't show obvious brittle behavior, because the sandstone, a sedimentary rock, mainly consisted of quartz and showed a brittle failure in uniaxial compression test, while the marble, a metamorphic rock, shown a plastic failure in uniaxial compression test. Therefore, the brittle property of rock itself determined whether the brittle failure mode occurred or not when rock fracture failed in the shear process, however, the brittle shear failure mode would not occur in the shear process of plastic rock fracture. What needs to be explained is that the failure of the brittle rock fracture can show brittle behaviors only under a high enough normal load. 


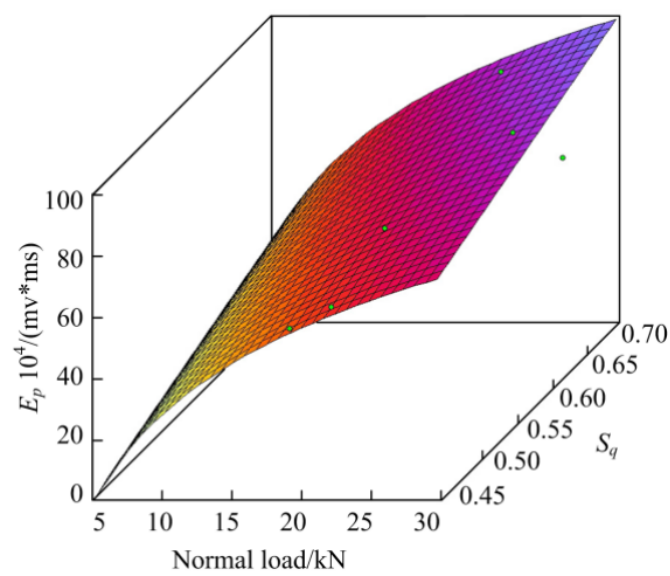

Figure 10: The relationships between peak $\mathrm{AE}$ energy $\left(E_{p}\right)$ and normal load $(N)$ and morphology coefficient $\left(S_{q}\right)$

According to Figure 7 in section 3.2, under the normal loads of $15-30 \mathrm{kN}$, the normal displacement of sandstone fractures decreased before the peak and increased sharply just after the peak, and the normal displacement of marble fractures increased before the peak and decreased gradually after the peak. Thus, normal deformation might be used to predict the brittle failure of sandstone fractures and the plastic failure of marble fractures under higher normal loads. It could be deduced that brittle failure mode might occur to sandstone fracture under higher normal loads while plastic failure mode occurred to sandstone fractures under lower normal loads and to marble fractures under all normal loads.

As mentioned in section 3.3, the high AE energy of sandstone fractures in Figure 8 was mainly released right after the peak while that of marble fractures in Figure 9 was generally released in the whole pre-peak stage from the beginning of the shear process. For sandstone fracture under higher normal loads, more and more elastic deformation energy would be stored in the asperities distributed on the fracture surface as shear stress increased. The greater the normal stress and the shear stress were, the more elastic deformation energy would be stored before the asperities reaching their elastic limit. Thus, brittle failure may happen to the sandstone fractures under higher normal loads accompanied by a sharp decrease of shear stress, big noise and violent shear shrink. But for marble fracture under all normal loads and sandstone fracture under lower normal loads, they would slide continually from the beginning of the shear test as shear displacement increased, and there would be no such an obvious sudden release of elastic energy as sandstone fractures.
It also could be guessed that entire dislocation of sandstone fracture under normal loads of $15-30 \mathrm{kN}$ should occur at the peak based on the sudden drop of shear stress (Figure 5a), the sudden increase of normal displacement (Figure 7a) and the sudden release of AE energy after the peak (Figure 8). Below, the failure process of sandstone and marble fractures would be studied by means of the $\mathrm{AE}$ method.

\subsection{Shear failure processes of sandstone and marble fractures}

The deformation and failure of rock fracture mainly happened to some contacted asperities, and the contacted asperities could be defined as the shear bearing asperities. Failure would occur to rock fractures as soon as these shear bearing asperities were cut off or worn. Generally speaking, the number of shear bearing asperities should be influenced by normal load and rock fracture surface morphology and influence the shear stress-shear displacement curve shape of rock fracture. When the rock fracture surface is smooth, the number of the shear bearing asperities will be small and does not increase obviously with increasing normal load; otherwise, when the rock fracture surface is relatively rough, the number of shear bearing asperities will increase with increasing normal loads or rock fracture surface roughness on the whole. Meanwhile, a larger number of shear bearing asperities would lead to a higher peak shear displacement and peak shear strength on the whole for same rock fractures. So, it is necessary to focus on the shear bearing asperities to identify the exact shear deformation and failure process of rock fractures.

Figure 13 depicts the initial fracture surface morphology and AE sources distribution evolution in the whole shear process of rock fractures. The high asperities (red zone) mainly located along the vertical axial of the rock fracture as shown in Figure 13(a) and the shear direction was along the vertical axial from top to bottom. When the contacted asperity of rock fracture surface was broken, there will be AE signals released from the broken asperity. It can be seen from Figure 13(a) that the AE signals generated mostly on the top half part of the rock surfaces near the vertical axial before the peak displacement of $2.37 \mathrm{~mm}$, which means there was no obvious real dislocation happened to the lower part of the rock fracture at this time. With the increasing of shear displacement, the AE sources points spread to the lower part of the rock fracture near the vertical axial after the peak displacement of $2.37 \mathrm{~mm}$, which can be seen as the sign of the dislocation of the lower part of the rock fracture. And then, the AE sources 

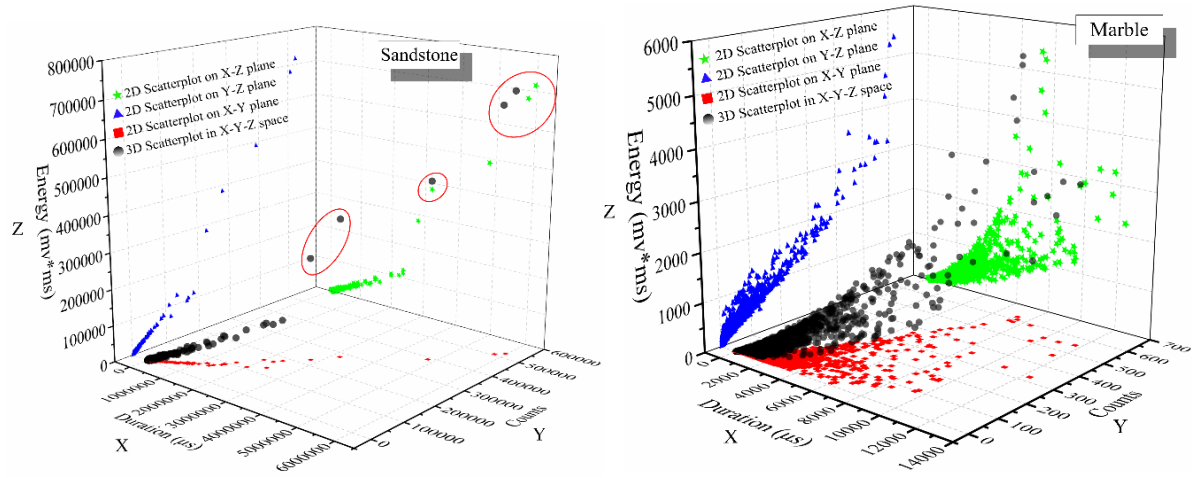

(a) The relationships among AE energy, duration and counts
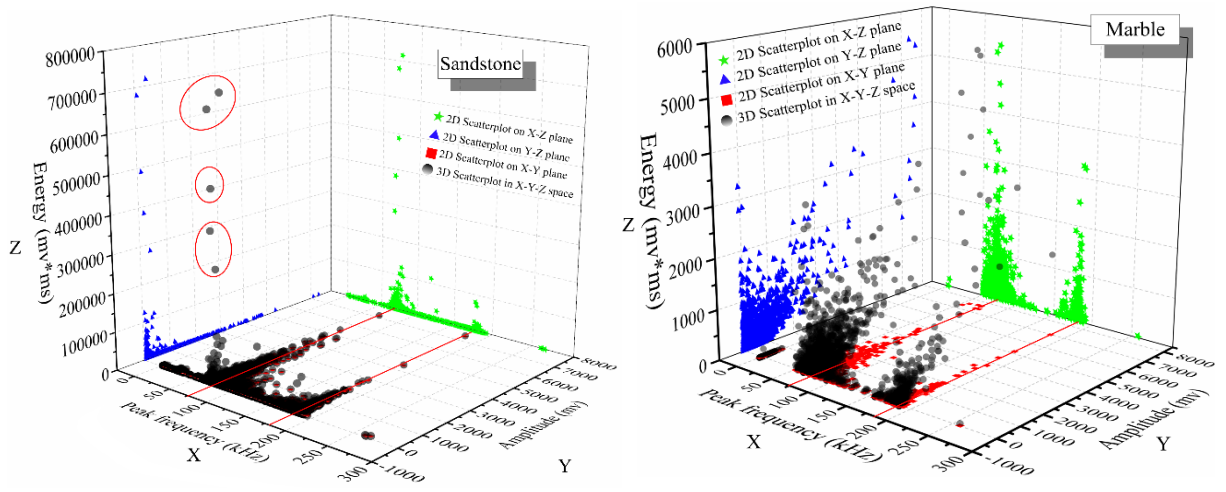

(b)The relationships among AE Energy, peak frequency and amplitude

Figure 11: The relationships between AE energy, duration, counts, peak frequency and amplitude. In Figure 11(a), solid black dots represent $A E$ events in X-Y-Z 3D space, red solid squares represent their projections on the X-Y plane to describe the relationship between AE counts and duration, blue solid triangles represent their projections on the $Y$-Z plane to describe the relationship between AE energy and counts, and green solid pentagons represent their projections on the $X-Z$ plane to describe the relationship between AE energy and duration. In Figure 11(b), solid black dots represent AE events in X-Y-Z 3D space, red solid squares represent their projections on the X-Y plane to describe the relationship between $A E$ amplitude and peak frequency, blue solid triangles represent their projections on the $Y$-Z plane to describe the relationship between $\mathrm{AE}$ energy and amplitude, and green solid pentagons represent their projections on the X-Z plane to describe the relationship between AE energy and peak frequency. Five typical AE signals highlighted in red loops with very high energy, count, duration and very low amplitude in sandstone fracture $\mathrm{S} 6$ were generated just after the peak.

distribution range had no obvious change, but the number of AE sources continued increasing with increment of shear displacement.

Moradian et al. [22] determined the entire shear dislocation of bonded joint by means of the AE method and concluded that there were almost no AE signals at the beginning of the shear test, and the number of AE signals increased rapidly to their maximum values when shear dislocation happened. Different from the bonded joints in reference [22], in this research, the non-bonded fractures generated $\mathrm{AE}$ signals right from the beginning of the shear test by mean of real-time AE source location method as shown in Figure 8 and 9. But for sandstone fracture $\mathrm{S} 6$ under the normal load of $30 \mathrm{kN}$, just like the shear dislocation of bonded joint in reference [22], the whole dislocation didn't occur at the beginning of the shear process but at the peak.

For sandstone fracture S6, as mentioned before, the AE source location mainly distributed on the upper half part of sandstone fracture near the vertical axial before the peak. It could be deduced that the broken shear bearing asperities on the upper part of sandstone fracture bore the shear load roughly by the sliding friction while the unbroken shear bearing asperities on the other parts of the rock fracture bore the shear load by the static friction according to the AE location distribution. Simply speaking, the bearing capacity of rock fracture $\mathrm{S} 6$ came from the sliding friction of the upper part and the static friction of the lower part of the rock fracture before the peak. Based on the presence of statically loaded regions, we consid- 


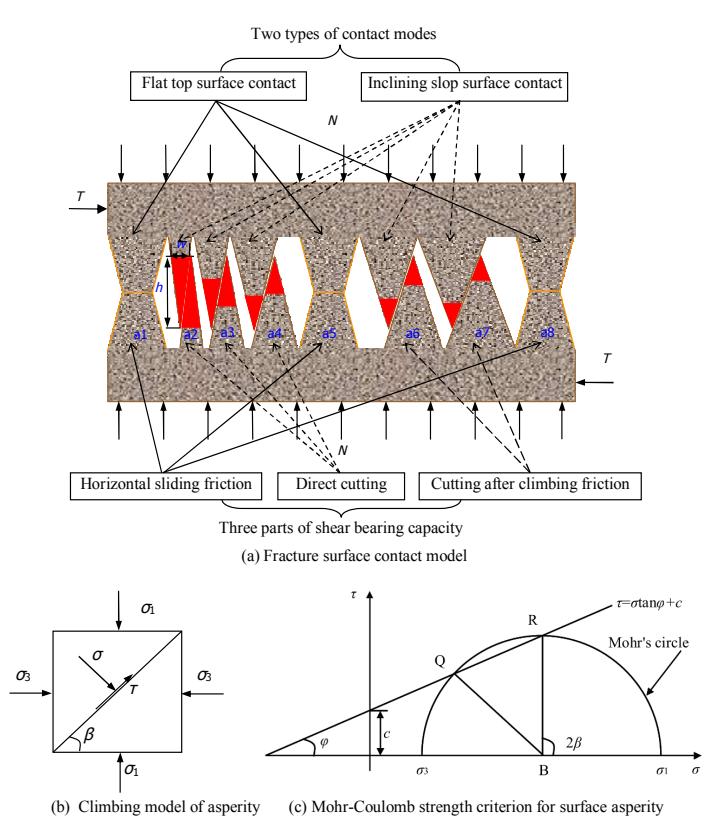

Figure 12: The shear failure model of rock fracture. Contact modes consist of a flat top surface contact and an inclining slop surface contact; Shear bearing capacity consist of horizontal sliding friction, direct cutting and cutting after climbing friction.

ered that the complete shear dislocation of the rock fracture S6 didn't occur before the peak shear displacement of $2.37 \mathrm{~mm}$. After the peak, AE location points dispersed and spread to the lower part near the vertical axial of the rock fracture. It could be concluded that the whole shear dislocation occurred right after the peak accompanied with a lot of AE signals generated from the break of the shear bearing asperities in the lower part of the rock fracture. And at this time, the sliding friction of the whole rock fracture provided most of the shearing resistance. Further, with the increment of shear displacement, more and more asperities were cut off and worn on the rock fracture, more and more AE signals occurred along the vertical axial of the rock fracture. And also, the rock fracture roughness and the shear stress became lower and lower. Above all, it could be concluded that, under a higher normal load, the whole shear dislocation of the sandstone fracture S6 happened just as the shear stress dropped after the peak accompanied with the damage of shear bearing asperities on the lower part of the rock fracture. However, the unbroken shear bearing asperities of other rock fractures before the peak did not always centrally distribute in a region like sandstone fracture S6, they might scatter in a certain amount on the fracture surface.

According to Figure 5(a), when the normal load was $10 \mathrm{kN}$ for sandstone specimen S2, the shear stress didn't drop obviously after the peak; and from Figure 13(b) we couldn't find the phenomenon that AE signals located only on a certain part of the rock fracture before the peak shear displacement of $1.25 \mathrm{~mm}$ and the AE signal location distribution had no obvious change before and after the peak like specimen S6. Thus, it could be deduced that the whole shear dislocation occurred just from the beginning of the shear test for the sandstone fracture under a lower normal load, because the lower normal load could not form relatively enough shear bearing asperities. Meanwhile, for the marble fracture A6 as shown in Figure 13(c), it could be found that AE signal sources were distributed on the fracture surface dispersedly before the peak shear displacement of $2.24 \mathrm{~mm}$ and had no obvious change after the peak. Also, the shear stress of a marble fracture had no obvious drop in most shear stress-shear displacement curves even under a higher normal load of $30 \mathrm{kN}$ in Figure 5(b). Thus, the evolutionary processes of AE signal source location of marble specimens were same as the sandstone fracture under a lower normal load, and the whole shear dislocation of the marble fracture occurred also from the beginning of the shear process just as the sandstone fracture under a lower normal load.

In addition, the normal displacement characteristics of rock fracture near the peak might also give reference to recognize the shear dislocation of sandstone fracture under a higher normal load, because a sudden change from shear dilatation to shear shrink of rock fracture occurred when the shear stress dropped right after the peak, which reflected the sudden breakage of the shearing bearing asperities.

\section{Conclusions}

(1) The post-peak drop gradient of sandstone fracture is much higher than marble fracture, which is about two orders of magnitude higher than marble fractures under high normal loads. Thus, the sandstone fractures fail in brittle state under a higher normal load for their shear stress drop suddenly just after the peak, while the marble fractures under each normal load and the sandstone fractures under lower normal loads fail in plastic state for most of their shear stress decreased gradually after the peak.

(2) When the normal load was lower, normal dilatation of both sandstone and marble fractures occurred almost in the whole shear process, while when the normal load was higher, shear shrink occurred finally with increasing shear displacement. Besides, normal displacement of sandstone fracture changed sharply from shear dilatation to shear 

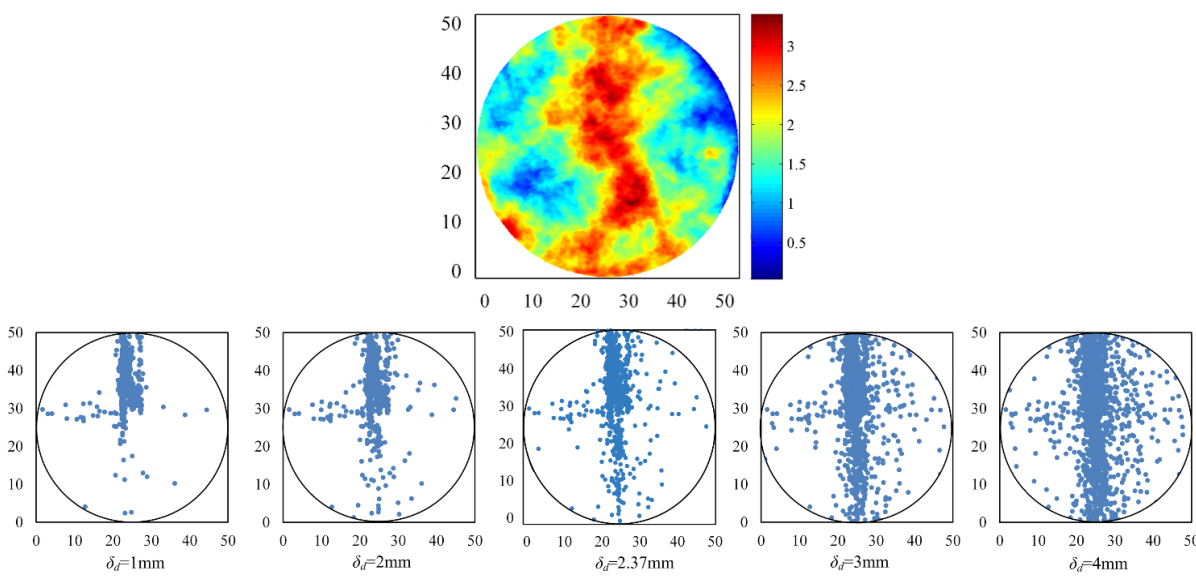

(a) Fracture surface topography and $\mathrm{AE}$ location evolution during the shear process of S6
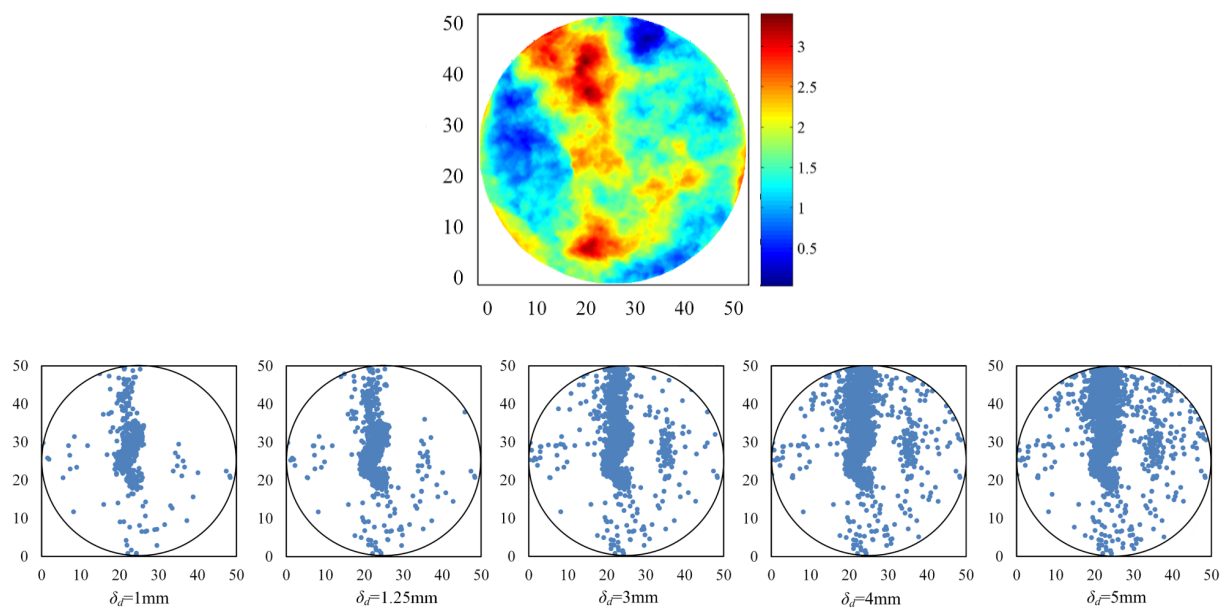

(b) Fracture surface topography and AE location evolution during the shear process of S2
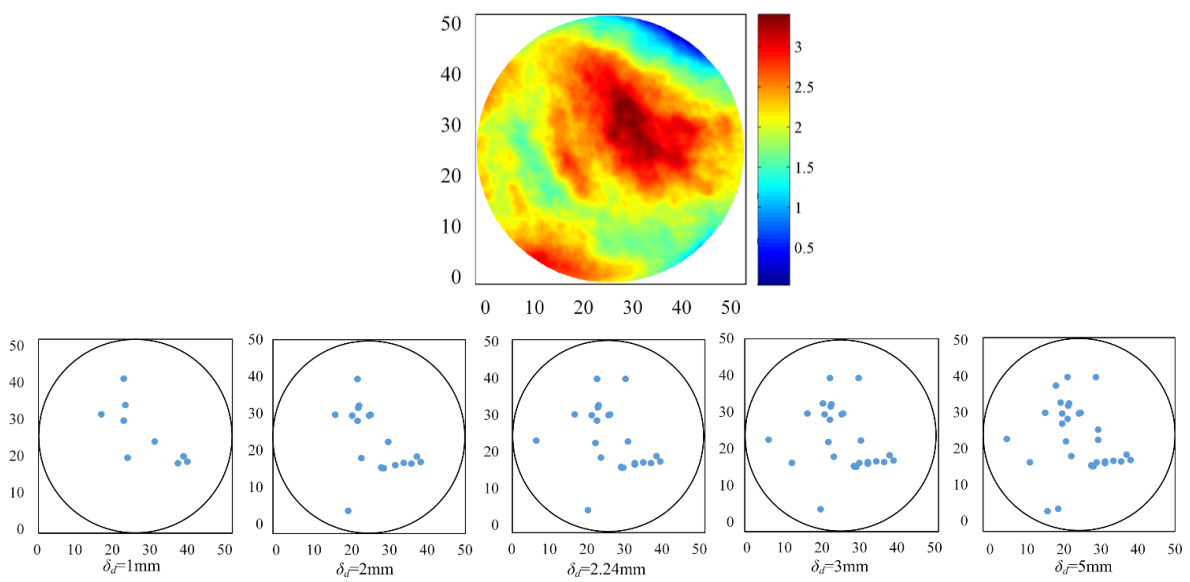

(c) Fracture surface topography and AE location evolution during the shear process of A6

Figure 13: Rock surface topography (upper image) and AE location evolution during the shear process (lower image). The red color means the higher zone and the blue color means the lower zone in upper fracture surface topography; a blue solid circle in lower image represents the location of an AE event. The shear direction was along the vertical axial from top to bottom. 
shrink just at the same time as the drop of the shear stress after the peak, thus the sharp change of normal displacement and the sudden drop of shear stress could be treated as the signs of the brittle shear failure of sandstone fracture under higher normal loads.

(3) AE signals with a high energy, a high count, a high duration, a low amplitude and a peak frequency of about $75 \mathrm{kHz}$ occurred just after the peak shear stress of sandstone fracture under the higher normal loads, which are corresponding to the sharp change from shear dilatation to shear shrink and the sudden drop of shear stress, thus the AE signals with high energies also can be used as signs of the brittle shear failure of sandstone fracture under higher normal loads. Besides, the peak AE energy of brittle sandstone fracture increased with increasing normal load and 3D root-mean-square deviation of the profile $\left(S_{q}\right)$ of fracture surface, which could be used for prevention and control of dynamic disaster relevant to rock fracture.

(4) The shear bearing capacity of rock fracture consists of the sliding friction from the contacted broken asperities and the static friction from the contacted unbroken asperities. For sandstone fractures under higher normal loads, some shear bearing asperities broke before the peak and other unbroken asperities would store great amounts of elastic energy. The whole shear dislocation of the sandstone fracture under higher normal loads, accompanied with the failure of unbroken shear bearing asperities, happened just as the shear stress dropped after the peak. But for marble fractures under all normal loads and sandstone fractures under a lower normal load, the whole shear dislocation occurred at the beginning of the shear process.

Conflict of interest: The authors confirm that this article content has no conflict of interest.

\section{References}

[1] R.W. Hutson, C.H. Dowding. Joint asperity degradation during cyclic shear. Int J Rock Mech Min Sci Geomech Abstr 1990, 27(2): 109-119.

[2] X. Huang, B.C. Haimson, M.E. Plesha, X. Qiu. An investigation of the mechanics of rock joints - Part I. Laboratory investigation. Int J Rock Mech Min Sci Geomech Abstr 1993, 30(3): 257-269.

[3] J.P. Pereira, M.H. Freitas. Mechanisms of shear failure in artificial fractures of sandstone and their implication for models of hydromechanical coupling. Rock Mech Rock Eng 1993, 26(3): 195-214.

[4] W. Wang, C.H. Scholz. Wear processes during frictional sliding of rock: a theoretical and experimental study. J Geophys Res 1994, 99(B4): 6789-6799.
[5] B. Indraratna, S. Thirukumaran, E.T. Brown, W. Premadasa, W. Gale. A technique for three-dimensional characterisation of asperity deformation on the surface of sheared rock joints. Int J Rock Mech Min Sci 2014, 70(9): 483-495.

[6] J.D. Byerlee. The Friction Characteristics of Westerly Granite. Cambridge, Massachusetts: MIT; 1966, Ph.D. thesis.

[7] F.D. Patton. Multiple modes of shear failure in rock. In: Proceedings of the 1st Congress of the International Society for Rock Mechanics. Lisbon; 1966: 509-513.

[8] J.A. Wang, H.P. Xie. Fractal evolution of surface damage of rock joints in shear. Mech Pract 1997, 19: 56-58.

[9] J.A. Wang, H.P. Xie, M.A. Kwasniewski. Fractal evolution and mechanical characteristics of surface roughness of rock joints in shear. J Geotech Eng 1997, 19: 2-9.

[10] H.P. Xie, J.A. Wang, W.H. Xie. Photoelastic study of the contact mechanics of fractal joints. Int J Mech Min Sci Geomech Abstr 1997, 34: 865-874.

[11] D. Lockner, The role of acoustic emission in the study of rock fracture. Int J Rock Mech Min Sci Geomech Abstr 1993, 30(7), 883-899.

[12] H.L. Dunegan, Fracture analysis by use of acoustic emission, Eng Fract Mech 1968, 1(1): 105-110.

[13] R.M. Koerner, W.M. McCabe, A.E. Lord. Overview of acoustic emission monitoring of rock structures. Rock Mech 1981, 14: 27-35.

[14] E. Eberhardt, D. Stead, B. Stimpson, R.S. Read. Changes in acoustic event properties with progressive fracture damage. Int J Rock Mech Min Sci 1997, 34: 3-4.

[15] V. Mlakar, F.P. Hassani, M. Momayez. Crack development and acoustic emission in potash rock. Int J Rock Mech Min Sci 1993, 30(3): 305-319.

[16] S.H. Chang, C.I. Lee. Estimation of cracking and damage mechanisms in rock under triaxial compression by moment tensor analyses of acoustic emission. Int J Rock Mech Min Sci 2004, 41: 1069-1086.

[17] C. Hong, J. Seokwon. Influence of shear load on the characteristics of acoustic emission of rock-concrete interface. Key Eng Mater 2004, 270-273: 1598-1603.

[18] B.K. Son, C.I. Lee, Y.J. Park, Y.K. Lee. Effect of boundary conditions on shear behaviour of rock joints around tunnel. Tunn Undergr Sp Tech 2006, 21: 347-348.

[19] N. Barton, V. Choubey. The shear strength of rock joints in theory and practice. Rock Mech Rock Eng 1977, 10(1): 1-54.

[20] C. Wang, B. Guo, L. Wang. Experimental Study on Relationship Between Mechanical, Seepage Characteristics and 3D Morphology Parameters of Marble Joint. The Open Civil Eng J 2016, 10 : 513-523.

[21] H. Dong, B. Guo, Y. Li, K. Si, L. Wang. Empirical formula of shear strength of rock fractures based on 3D morphology parameters. Geotech Geolog Eng 2017, 35(3): 1169-1183.doi: 10.1007/s10706-017-0172-5.

[22] Z.A. Moradian, G. Ballivy, P. Rivard, C. Gravel, B. Rousseau. Evaluating damage during shear tests of rock joints using acoustic emissions. Int J Rock Mech Min Sci 2010, 47(4): 590-598. 